\title{
Structural Steels of High Elastic Limit.
}

$\mathrm{T}^{\mathrm{T}}$ HE demand for stronger, but still relatively cheap, steels in shipbuilding, and in bridge and boiler construction, etc., gives considerable importance to a paper on the subject recently presented by $J$. A. Jones to the Iron and Steel Institute.

It is well known that it is possible to increase the elastic limit and tensile strength of the steel by an increase in the carbon content, but a comparison of steels with identical maximum strengths shows that this method of securing high-tensile properties is much less satisfactory than by increasing the amount of manganese present. A higher carbon steel, with a given maximum strength, has a lower elastic limit, yield point, and elongation, and a much lower impact value than a lower carbon steel of similar tenacity obtained by the addition of more manganese. Its fatigue range is also lower than that of a low-carbon high-manganese steel, and it is, further, much more affected by slight departure from the most suitable conditions of normalising.

The improvement in the properties of these steels by the addition of manganese is very marked, but the amount present must be limited to a figure which varies with the carbon content. With $0 \cdot 2$ per cent of carbon, a suitable maximum percentage of manganese is 1.8 per cent, which falls to 1.5 per cent when the carbon content is increased to 0.35 per cent. These figures apply particularly to sections $\frac{3}{4}$ in. thick; the limits of manganese content being rather lower for thinner sections. A small amount of nickel increases the ductility of low carbon steels, but at least 3 per cent of this element is required to produce a steel belonging to the high elastic limit class, and it is suggested that the use of a small amount of chromium at a lower cost would appear to be more promising.

The influence of silicon in raising the elastic limit and tensile strength of mild steel has been known for a long time, and much interest has been shown in Germany lately in a steel containing about $0 \cdot 1$ per cent of carbon, 0.5 to 1.5 per cent of manganese, and 0.6 to 1.5 per cent of silicon. The tensile strength of this material is from 30 to 35 tons per square inch, but with a higher carbon content, increased tenacity may be obtained. The test results given show clearly that silicon raises the fatigue range and the ratio of the fatigue limit to the tensile strength to a greater extent than does manganese. With a silicon content of 1.5 per cent, however, a marked lowering of the impact figure occurred, and no silicon steel was found with all-round properties superior to those of a plain manganese steel containing 1.5 per cent of that element. Further, the higher silicon steels present certain difficulties in manufacture. The steel pipes deeply, involving a high percentage of discard, higher temperatures are required for annealing and rolling, and greater care must be exercised in reheating, in order to avoid cracks.

Owing to these difficulties in the production of silicon steel on a large scale, a new structural steel is being developed, containing approximately : carbon $0 \cdot 15$ to $0 \cdot 18$, silicon $0 \cdot 25$, manganese $0 \cdot 8$, copper 0.5 to 0.8 , and chromium 0.4 per cent. The amount of scrap produced is small, and in spite of the additional cost of the special elements, the steel can be produced more economically, and with more reliability than can the silicon steel. It has a lower tensile strength than the steels considered in Mr. Jones's paper, but an increase in the carbon with an adjustment of the copper and chromium contents might lead to the development of a high quality steel with a high limit of proportionality and good ductility.

On the whole, it is concluded that of the materials examined a steel containing $0 \cdot 3$ per cent of carbon, 1.3 per cent of manganese, and 0.9 per cent of silicon yields the best mechanical properties. Normalised at $860^{\circ} \mathrm{C}$., this steel gave the following test results :

Elastic limit.

Yield point

Maximum stress

Elongation

Reduction of area

Brinell hardness

Izod impact value $26 \cdot 8$ tons per square inch.

$29 \cdot 8,, \quad$,
$45 \cdot 6$," ,"
30 per cent.
63 ," ,"
200 ft.-lb.
44 .

, ,

(n)

F. C. T.

\section{Scientific Uses of Gramophone Records.}

THIRTY years ago, the possible use of gramophone records in phonological studies was realised and discussed at a meeting of the Vienna Academy of Sciences. Since then, large collections have been formed of records of all the European languages and dialects and of the speech and music of many of the primitive peoples. In archives are preserved at Vienna some 3000 records, at Paris 4000, at Berlin 10,000, and collections of similar size are to be found at important centres in all parts of the world. The first use of gramophone records in the exact sciences was in a rather premature attempt to analyse the physical nature of vowel sounds. Enlarged tracings of the grooves were obtained by a lever system from the slowly rotating record and were assumed to represent the original sounds.

Until quite recently no systematic research had been carried out upon the gramophone, but during the last few years the new electro-mechanical acoustics has been applied and has made possible the preparation of records of special value for many electrical and acoustical laboratory measurements and experiments. The Parlophone Co. has issued a set of three sound test records ${ }^{1}$ prepared under the direction of Drs.

1 Sound Test Records. Three 12-in. d.s. with album and instructions. Obtainable only from Parlophone Co., Ltd., 85 City Road, E.C.1. 42s. net.

No. 3132, VoL. 124]
E. Meyer and H. Salinger, of the Hertz Institute, Düsseldorf. The first record gives on one side when rotated at a speed of 80 revolutions per minute an almost pure sine wave output beginning at a frequency of 6000 and steadily gliding down to 100 Hertz (1 Hertz = l vibration per sec.). To overcome the difficulty of the stationary waves set up when such a record is used to obtain acoustical response curves with fixed apparatus in an ordinary room, the other side of the record is prepared to give a "gliding howling' tone the frequency of which varies about 10 times per second by $=50$ cycles, whilst the mean frequency decreases as before steadily from 6000 to 150 cycles. The system of nodes and antinodes in the room is, therefore, continually shifting. The other records of howling tones give a frequency band which is traversed about 10 times per second, whilst the mean frequency remains constant at a selected one of eight possible values.

The Gramophone Co. (H.M.V.) also issues a list of fifteen double-sided 12-in. constant frequency records, which, when rotated at a speed of 78 revolutions per minute, are capable of giving any one of 100 different frequencies of 50 seconds duration, of which the lowest is 25.5 and the highest 8460 cycles. Many possible uses of these special records are indicated in the technical press, the Parlophone Co.'s leaflet, 